\title{
EL SIGNIFICADO DEL CONCEPTO DE EQUIDAD EN ALBERTO MAGNO Y EN TOMÁS DE AQUINO
}

José Ricardo Pierpauli*

SINTTESIS - El presente artículo tiene por objeto mostrar la armónca integración de las doctrinas de la Equidad en las Filosofias Prácticas de Alberto Magno y de Tomás de Aquino. Las soluciones que ambos autores ofrecen permiten extraer importantes elementos de juicio a fin de resolver el importante problema de la Filosofía Política y Junídica actual a saber, el del modo de determinar la medida de la Justicia que sirve como situación de partida para la formación y regulación de la Comunidad Politica. El texto está compuesto de cuatro partes principales. En primer lugar se puntualiza la inclusión del tema dentro de los problemas de la Filosofia Práctica actual. En segundo lugar se fomulan algunas presiciones histónico filosóficas que servirán luego de apoyatura para delinear las doctrinas de los autores tratados. Aquí mismo se presenta una sistemática amplia acerca del concepto de Equidad en la cual quedan integrados los rasgos comunes que las historia del concepto desde la antigüedad hasta la Edad Media permite bosquejar. En tercer lugar se ofrecen las doctrinas de Alberto y de Tomás, poniendo especial atención tanto a la presentación de los textos pertientes como a su acuerdo sea entre un autor y el otro, como también respecto de la tradición llamada iusnaturalista. Por último se extraen algunas conclusiones mediante las que se pretende abrir un debate posterior centrado en la misma perspectivca del presetne estudio a saber, revalorizar la inclusión de las argumentaciones de Alberto y de Tomás en las cuestiones más actuales de las Filosofias: Politicas y Junídicas.

PALABRAS-CLAVE - Filosofía Medieval. Política. Alberto Magno. Tomás de Aquino. Equidad
ABSTRACT - The present article has for object to show the harmonically integration of the doctrines of the Justness in Albert the Great's Practical Philosophies and Thomas Aquinas'. The solutions that both authors offer allow to extract important trial elements in order to solve the important problem of the current Political and Juridical Philosophy that is, that in the way of detemining the measure of the Justice that is good as departure situation for the formation and regulation of the Political Community. The text is made up of four main parts. In the first place the inclusion of the topic is remarked inside the problems of the current Practical Philosophy. In second place some philosophical historical precisions are formulated that will serve after as support to delineate the doctrines of the treated authors. Right here a system is presented wide about the concept of Justness in which are integrated the common features that the history of the concept from the antiquity until the Middle Age allows to sketch. In third place are offered Albert's doctrines and Thomas's, putting special attention so much to the presentation of the pertinent texts as to their agreement it is between an author and the other one, as well as regarding the tradition called iusnaturalistic... Lastly some conclusions are extracted by means of those that seeks a later debate centered in the same perspective of the present study to open up that is to revalue the inclusion of Albert's and Thomas's arguments in the most current questions in the Philosophies: Political and Juridical ones.

KEY WORDS - Medieval Philosophy. Politics. Albert the Great. Thomas Aquinas. Justness.

* Universidad Nacional de Córdoba/Argentina.

\begin{tabular}{|l|l|l|l|l|l|}
\hline VERITAS & Porto Alegre & v. 44 & n. 3 & Setembro 1999 & p. 659-668
\end{tabular}


La resolución de situaciones controvertidas mediante los juicios de Equidad en las obras de Alberto y de Tomás significó el recurso a la Lex divina. Aquella divinidad, constituida en centro de referencia, tenía contornos perfectamente determinados e incontrovertibles, de tal modo que el arbitrio de sobrepasar el sistema jurídico positivo mediante el llamado Derecho Natural o, lo que es lo mismo, a través de la revivificación del Derecho a partir de sus principios fundamentales, se entendió como la adecuación de la Ley Divina de conformidad con la razón humana. De este modo pudo allanarse el camino para reencauzar la ley positiva en vistas no solo de su fin inmediato, esto es, el reestablecimiento de la igualdad entre las partes en el caso controvertido, sino también el del su fin mediato a saber, la concreción del Bien Común Político.

La situación actual de la Filosofia Política y de la Jurídica, ambas desarrollándose y transformándose dentro de una esfera intercultural de una complejidad significativamente mayor que aquella que contomeaba a la Civitas durante la Edad Media, no admite - tal como equívocamente se le asigna al iusnaturalismo - la transferencia directa de una Ley Sobrenatural respecto de las cuestiones problemáticas que afectan la convivencia. El hecho del desplazamiento de la Teología y de la Metafísica de la esfera de la argumentación de lo jurídico y político, dió lugar al reemplazo del punto de partida extra-jurídico por otro principio de carácter político al que, por ser el resultado de un procedimiento consensual, ${ }^{1}$ se le atribuye la nota de incuestionabilidad. Así pues, sigue siendo indiscutible, la urgencia del recurso a principios valorativos de tipo extra-jurídicos.

Alberto y Tomás en las antípodas de John Rawls, consideran a la Justicia Política como medida de la Comunidad Política. Para ambos la Política consiste tanto en la transformación racional de la Ley Natural en Positiva, de conformidad con las circunstancias, ${ }^{2}$ como en la creación de normas jurídicas y en su aplazamiento, a partir del ejercicio del poder de la autoridad, toda vez que aquellas circunstancias lo requieran. La economía sobrenatural se traduce a términos políticos y jurídicos dentro de ambos sistemas, a través de la adaptación del contenido ético del primer principio práctico, según las circunstancias históricas, en un concepto de Justicia Política que sirva como punto de partida y medida de las estimaciones normativas del orden político considerado como un todo.

La Equidad es una cierta virtud reguladora no solo del obrar del gobernante y del juez, sino también del hombre, considerado como parte de la comunidad política. La norma de conducta (moral, política y/o jurídica) que la Equidad permite elaborar, representa el trasunto deontológico de la armonía pre-política que la Razón Práctica tiene por delante y que se ha llamado hasta ahora orden natural.

1 Aludo aquí a la posición de partida formulada por John Rawls en la cual el concepto de Justicia Política es antes que la proyección de un concepto inmutable, el producto de una elaboración racional que todos aceptan a favor de una mejor convivencia y al que se ha dado en llamar Teoria Procedimental de la Justicia Política:

2 Un examen acerca de la importancia de las circunstancias en el campo ético y jurídico, desde la perspectiva de Tomás de Aquino puede hallarse en la muy reciente obra de Thomas Niesters, Akzidentien der Praxis, Alber Verlag, Freiburg-München, 1992, especialmente en su capitulo IV. 
La Equidad es al mismo tiempo una elaboración de la Razón Práctica que, aunando en un juicio práctico el contenido de eticidad de los primeros principios y los aspectos relevantes de las circunstancias que rodean nuestro obrar, permite ordenar nuestras acciones en vistas de la Felicidad Política.

\section{Algunas notas histórico-filosóficas respecto del concepto de Equidad}

El problema de la Equidad ocupó un lugar importante dentro de los sistemas de Platón y de Aristóteles. El primero de ambos filósofos antiguos examinó la cuestión en El Político, ${ }^{3}$ preocupándose allí por la posibilidad de un gobiemo sin leyes. Platón comienza por distinguir aquello que seria también objeto de distinción en el Libro Primero de la Política de Aristóteles ${ }^{4}$ a saber, que si bien resulta claro que una ley o un grupo de éstas no podrian abarcar la totalidad de los casos posibles, sí en cambio puede hacerlo un hombre, a saber, aquel que mediante sus desiciones politicas prudenciales ejerce la tarea de gobierno. Las leyes positivas constituyen unas ciertas creaciones de la autoridad derivadas en parte, de un orden normativo preestablecido y que vienen a constituir algo así como el entramado a través del cual conviene que transiten los súbditos, a fin de alcanzar la felicidad política.

El Filósofo reitera la pregunta de Platón a saber, si es más ventajoso el gobierno de un hombre o el de la ley, ${ }^{5}$ afirmando que sin duda, conviene que el gobierno sea cuestión de los hombres, pero de conformidad con una cierta regla general. ${ }^{6}$ El texto de Aristóteles debe subordinarse al pasaje 1137 a 31 de la Ética a Nicómaco pues es allí y en la Retórica 1374 a $27^{7}$ donde examina el concepto de Equidad alcanzando la dimensión múltiple ${ }^{8}$ que a mi juicio, tiene también en Alberto y en Tomás. Celso y Ulpiano por su parte, ambos jurisconsultos pertenecientes al llamado período clásico, sostuvieron que el Derecho es o bien un ars boni et aequi o bien una ex boni et aequi scientia (Digesto I, 1, 10, 2) Ulpiano completó el sentido de su determinación diciendo, también en el Digesto: quod

\footnotetext{
Cfr. Platón, El politico, 294 a 7, Wissenschaftliche Buchgesselschaft, Darmstadt 1970, pag. 523

Cfr. Aristóteles, La politique, 1252 a 7, Tr. J. Tricot, Vrin, 1989, p. 22.

Cfr. Aristóteles, La politique, 1286 a 7, ed. citada.

Cfr. Aristóteles, La politique, 1286 a 15, Ed. citada.
}

Dice alli el Filósofo: "Ser indulgente o comprensivo con las cosas humanas es ser equitativo, y también lo es mirar no a la parte sino al todo; no que tal es el acusado ahora, sino como era siempre y de ordinario. También es equitativo acordarse más de los bienes recibidos que de los males: y más de los bienes que ha recibido uno que de aquellos que hizo. Y es equitativo el haber soportado la injusticia recibida. Y el preferir resolver litigios de palabra que de obra. Y es también equitativo el querer recurrir mejor a un arbitraje que a un juicio; porque el árbitro atiende a lo equitativo, y en cambio el juez a la ley; y con este fin se inventó el árbitro, para que domine la equidad." Cfr. Vallet de Goytísolo, Metodología de la Determinación del Derecho II, Ed. Areces, Madrid, España, 1996, p. 1451.

8 El texto que sigue, tomado del Digesto, reúne en una sola fórmula la amplitud del concepto de Equidad: In ornnibus quidem, maxime tamen in iure aequitas spectanda est, Dig. 40.17.90. Cfr. Bien G., Billigkeit, en Philosophisches Wörterbuch, p. 939-940

9 Cfr. Vallet, Metodología de la determinación del Derecho, Parte Sistemática, Ed. Areces, MadridEspaña, 1976, p. 1440 
semper aequum ac bonum est ius dicitur, ut est ius naturale..$^{10}$ Por último Cicerón opina, igual que los jurisconsultos, que una cierta igualdad o armonía es la nota distintiva del Derecho: valeat aequitas quae paribus in causis paria iura desiderat."

Los textos presentados reconocen en común la necesidad de condensar en una norma positiva o en una desición política, aquella armonía que está en el origen de toda creación humana. La formación misma de la comunidad política a partir de una ley fundacional - que bien podrían ser nuestras actuales Constituciones Jurídicas - requiere la aplicación del concepto de Equidad, pues a través de su contenido la Razón Práctica, en este caso la del gobernante, puede trazar las líneas directrices que sirven de orientación para el obrar político. La tarea creativa y ordenadora de la Razón del gobemante permite formular una cabal interpretación y la traducción correspondiente del ethos de una comunidad política determinada. Este será luego el ámbito de legitimación moral tanto del obrar de los súbditos del todo político como de sus gobernantes.

Las posiciones de Alberto y de Tomás receptan la significativa transformación que el significado deontológico de la naturaleza experimentó en Agustín de Hipona. En efecto, mientras que para Cicerón la naturaleza estaba identificada con una cierta divinidad, para el Obispo de Hipona en cambio, debía distinguirse entre la naturaleza como tal y la divinidad, que inscribe sobre ella sus leyes, las cuales solo pueden ser descubiertas por la Razón humana con ayudad de la Gracia. ${ }^{12}$ La configuración del juicio de Equidad quedó de este modo subordinado a la Teología.

Desde una perspectiva sistemática resulta posible ofrecer la lógica articulación de los diferentes niveles que envuelven y condicionan la tarea regulativa de la razón. Así pues, reconocemos una dimensión sobrenatural cuya economía resulta visible solo parcialmente en el orden de la naturaleza. Frente a ella se ubica el hombre con su Razón reguladora. La Razón humana es también naturaleza, pero está dotada como aquella en su totalidad, de un rasgo de la economía sobrenatural a saber, de su innata ordenación hacia un cierto bien.

A su vez ese bien hasta ahora solo formaliter, alcanza su concreción cuando la Razón Práctica confronta aquel imperativo innato con los datos recogidos de la realidad. La conclusión será entonces ecuánime cuando el bien hacia el que el hombre está orientado pueda realizarse, según la ordenación racional de lo real. La Razón Práctica busca captar mediante este silogismo, el orden intrínseco de las acciones que se propone normar, a fin de que esa textura interior, lograda por vía de la abstractio quiditativa, sirva como medida del obrar recto. La norma del obrar será entonces buena y equitativa. Buena por cuanto en virtud de su rectitud se dirige directamente hacia el Bien y ecuánime por cuanto en la armonia de la norma se refleja analógicamente la armonía del orden del todo de la naturaleza.

Vallet, op. cit., p. 1453

$"$ Cicerón, Tópica, IV-23. En Vallet de Goytísolo, Metodologia de la determinación del Derecho, Ed. Areces, Madrid - España, 1996, p. 1453.

12 Krieger G. - Wingendorf R., Christsein und Gesetz: Augustinus als Theoretiker des Naturrechts, en: Horn Ch. Hgs, De Civitate Dei, Akademie Verlag, Berlín, 1997, p. 238. 
Examinemos ahora las determinaciones más precisas de la Equidad. El juicio de Equidad que aplican en sus razonamientos prácticos tanto el gobernante, el juez, como el ciudadano, tiene una dimensión creativa cuando, frente a una conjunción circunstancial de diversos factores, formula concretamente una norma, sea moral, política y/o jurídica. La intención del legislador. que fue el móvil del nuevo precepto obligatorio, queda en cierto modo enclaustrada en el interior de su creación, esto es en el núcleo ético de la norma. De este modo la norma aparece incluida, como un polo referencial, en el interior de una situación problemática a la que se intenta regular. Quedan pues enfrentados dos elementos, uno estático a saber, la norma y otro de carácter dinámico, es decir, las circunstancias que son objeto de regulación. Cuando la movilidad de los factores que componen las circunstancias alcanza un grado significativo de variabilidad a punto tal de quedar fuera del horizonte comprensivo de la pauta obligatoria, se hace necesaria y aun urgente la adopción de uno de los dos criterios siguientes, o bien se crea una norma completamente diferente o bien, si es que aquellas circunstancias han variado mucho o poco, pero permanecen con todo ligadas al hecho básico que es objeto de la norma originaria, procede la rehabilitación del núcleo ético de ésta, ya sea supliendo los defectos de una norma preexistente o atenuando su rigor. : Se trata en este último caso de la aplicación más vulgar del juicio de Equidad.

Tanto en el acto de creación de las normas como en el de rehabilitación de su sentido fundamental, se aplica el juicio de Equidad pues, en un todo de acuerdo con las definiciones clásicas precitadas, es condición de la norma no solo su encaminamiento hacia el Bien, sino su equilibrio respecto del todo en el que la misma se integra. Se entiende aquí por todo al conjunto de los factores históricos $\mathrm{y}$ al orden inmutable de la naturaleza, tanto del hombre y de las pautas de su razonamiento, como de la acción que debe regularse.

Otras aplicaciones del juicio de Equidad, además de la creativa y correctiva dividida a su vez esta última en suspensivas y supletivas - muy suscintamente enunciadas, provienen del sentido de benignidad exigido tanto por la amistad que está en la base del orden político como del Bien Común Político. Así y en acuerdo con el Estagirita, adquiere su significado técnico el dicho popular a saber, es mejor un buen arreglo - entre las partes - que un buen juicio. Ello por cuanto en el arreglo interviene por lo general un árbitro quien, a diferencia el juez, no mira de un modo principal la ley, sino el interés que las partes tienen por alcanzar lo justo. Otras veces surge de la aplicación rigurosa de la norma no solo el restablecimiento de lo justo, sino una cierta lesión de la amistad y de la concordia entre las partes. Así pues, si es que el desajuste entre las partes lo permite porque de su ajuste no depende directamente el Bien del todo, convendrá antes el perdonar la ofensa y olvidar la injusticia recibida. Así mismo y siempre dentro del nivel ético monástico, será mejor olvidar los favores realizados en beneficio de otro y recordar más bien los recibidos, ello nos hace recordar al mismo tiempo antes nuestro débito respecto de nuestros semejantes que el débito de Justicia del que somos tal vez legítimos acreedores. También aquí nos ilustra el decir popular hoy por $t i$, mañana por mi. Esta última dimensión monástica de la Equidad, aludida espe- 
cialmente por Aristóteles y por Alberto Magno pone en evidencia la recíproca y muy dinámica relación que existe entre dos esferas relevantes para la vida política, ellas son la del amor y la de la Justicia, ${ }^{13}$ sea ésta en su forma prescriptiva o bien en su forma coactiva.

\section{Alberto Magno y Tomás de Aquino a propósito del concepto de Equidad}

Alberto a diferencia de Tomás, ${ }^{14}$ ofrece en el punto de partida de su examen de la Equidad una determinación etimológica ${ }^{15}$ que será luego ampliamente utilizada en su Comentario a los Libros de la Política de Aristóteles. En la interpretación del Doctor universalis se trataria de una cierta sobre Justicia. Se trata de un juicio de la Razón Práctica y por tanto su fuente es doble, de una parte la Justicia llamada legal y de otra la actividad de la Razón, como causa eficiente próxima del juicio de Equidad. ${ }^{16}$ Para el Doctor universalis es especialmente significativa la tarea creativa del gobernante y/o del legislador como órganos que personifican una cierta Justicia viviente. Así, podría terciar Alberto en el diálogo entablado por Platón en El político 294 a 7 y sgts., diciendo que efectivamente, la ciudad puede ser gobernada aun con pocas leyes, toda vez que el gobernante pueda extraer del sentido esencial de la Justicia Política, la respuesta para todas aquellas situaciones controvertidas e impensadas al momento de crear los preceptos legales positivos.

Según Alberto ${ }^{17}$ la exactitud matemática no es precisamente un atributo de las ciencias llamadas prácticas. Mas este hecho no impide que los juicios que integran estas ciencias estén revestidos de valor científico. Aplicado al problema de la Equidad, debe decirse que desde el punto de vista de la materia variable que son las circunstancias, no puede constituirse ciencia alguna, debido a que, faltaría la universalidad requerida. Sí en cambio es científico el juicio normativo, en nuestro caso el juicio de Equidad, pues su universalidad radica tanto en el principio práctico inmutable - radicado en la sindéresis - desde el cual se formulan las conclusiones, como en el modo de concluir. ${ }^{18}$ Dicho de otro modo, la cientificidad del

13 Cfr. Vallet de Goytísolo, En tomo al Derecho Natural, Ed. Saial, Madrid - España, 1973, p. 7.

14 Tomás solo se limita a determinar el significado esencial de la Equidad que según vimos, recoge de los jurisconsultos romanos. Dice el Aquinate: epieikia, quae apud nos dicitur aequitas. Summa Theologiae, I-II, Q. 120, Art. 1, Ed. Leonina, Roma 1888 Tomás recogió la determinación etimológica de Alberto recién en el Artículo segundo de la Cuestión 120. Allí dice el Angélico: "dicitur enim ab epi, quod est supra, et dikaion, quod est iustum". Por su parte aclara Tomás Vio Cayetano "quid est epieikia, seu aequitas, ut latine loquamur in lingua latina".

Dice Alberto: "eipeikia dicitur ab 'epi', quod est 'supra' et 'dicaion', quod est iustitia, quasi 'supra iustitiam'; et virtus nominis est 'quasi per se iustitia'." Albertus Magnus, Super Ethica (E-I), Ed. Coloniense, T. XXIV, Aschednoprf, 1968-72, p. 379-10.

"Iustitia enim legalis regulatur in suis operibus secundum praecepta legis, sed ubi lex deficit in particularibus casibus, quae universaliter promulgata est ad plura respiciens, epieikes quis operatur rectum per seipsum et supplet defectum legis..." (Albertus Magnus, op. cit., p. 379-13 y sgts.)

"Universale secundum praedicationem non est certum in moribus et per hunc modum lex non est universalis, sed quantum ad casus, et haec est universalitas operum, et hoc materialiter est legem esse universalem" (Albertus magnus, op. cit., p. 380-80).

18 "Sine praeiudicio dico, quod syndersis est specialis vis animae, in qua secundum Augustinus universalia iuris descripta sunt: sicut enim in speculativis sunt principia et dignitates, quae non addiscit homo, sed sunt in ipso naturaliter, et iuvatur ipsis ad speculationem veri: ita ex parte 
juicio de Equidad consiste en la validez de un principio universal en los casos concretos. Precisamente el menester del jurista y del gobemante en su tarea legislativa, ${ }^{19}$ consiste en reducir la multiplicidad de casos posibles a un cierto compendio sistemático de normas, ${ }^{20}$ limitado por naturaleza, y animadas todas ellas por el sentido dominante de la Justicia Política. Este sistema al que con terminología moderna podríamos llamar abierto, alcanza su completitud cuando, ante la configuración de un caso no previsto por las normas del sistema, es posible con todo, su resolución, pues el legislador crea una noma, suspende el rigor de una ya existente, o bien suple los defectos de ésta, por imposición de la variabilidad de la materia.

Tanto para Alberto como para Tomás el problema de los juicios de Equidad se reduce a una cuestión de juicios prácticos. Esto significa que en los mismos está implicada la totalidad de la persona que los elabora, sea este el gobernante o el simple ciudadano. El juicio ecuánime convierte en justo a quien lo emite $\mathrm{y}$, por el contrario, el juicio inecuánime transforma a aquel en un transgresor de la Justicia. Para Alberto el juicio de Equidad se alcanza a partir de la firme posesión del hábito de la Justicia, ${ }^{21}$ de tal modo que quien lo posee es capaz de obrar de conformidad con normas ecuánimes, aun cuando la ley positiva no existiera. El juicio de Equidad es, para el Doctor universalis, un constitutivo esencial de la ley moral o lo que es lo mismo de la ley de la conciencia.

Considerado desde sus aspectos jurídicos y políticos, el juicio de Equidad reconoce como su ámbito propio al de lo Justo ${ }^{22}$ al que debe entenderse a su vez, como parte constitutiva del Bien Político. ${ }^{23}$ La Equidad está referida no a la ley positiva, ni al contenido de Justicia que encierra, sino más precisamente a la correspondencia o mejor dicho a la proporcionalidad ${ }^{24}$ que existe entre la norma posi-

operabilium quaedam sunt universalia dirigentia in opere, per quae intellectus practicus iuvatur ad discretionem turpis et honesti in moribus, quae non discit homo, sed secundum Hieronymus est lex naturalis scripta in spiritu humano. Et dicuntur ab Augustino universalia iuris, sicut est non esse fornicandum, et non esse occidendum, et afflictio esse compatiendum, et huiusmodi: et subiectum illorum synderesis est: et propter hoc ab Augustino vocatur naturale iudicatorium..." (Albertus Magnus, Suuma de creatirus, E. A. Borgnet, Paris, 1896, tomo 35, Q. 71, art. 1).

19 "Cum enim casus sint infiniti, oportuit, quod ars dirigens in illis colligitur in quoddam finitum compendium infinitorum, quia infinita non cadunt sub cognitione. Et ideo non potuit esse, quod lex prosequeretur omnes casus, sed quantum fieri potuit, sub universali edicto eos conclusit; tamen propter multos varios eventus non potuit esse, quod illud applicaretur ad omnes. Et ideo oportet, quod in hoc epieikes suppleret defectum legis, alis civilitas non esset perfecta" (Albertus Magnus, op. cit., p. 381-1-10).

${ }^{20}$ Vale decir, lo que hoy llamamos códigos.

21 "Iustitia dupliciter potest considerari: aut secundum quod reddere unicuique, quod suum est, determinatur iure, et sic pertinet iustitia ad civilem, cuius est ius statuere et legem ponere; aut secundum quod determinatur voluntate, inquantum aliquis vult reddere cuilibet, quod suum est, et redderet etiam, si lex non esset, secundum quod inclinatur habitu relicto ex similibus operationibus..." (Albertus magnus, op. cit., p. 306-47).

22 "Epiekia est in genere iustitiae [...] secundum ambitum..." (Albertus Magnus, op. cit., p. 380-8).

23 "Cum de legibus ageretur, quia humani actus, de quibus leges dantur, in singularibus contingentibus consistunt, quae infinitis modis variari possunt, non fuit possibile aliquam legis institui quae in nullo casu deficeret: sed legislatores attendunt ad id quod in pluribus accidit, secundum hoc legem ferentes; quam tamen in aliquibus casibus servare est contra aequalitatem iustitiae, et contra bonum commune, quod lex intendit" (Tomás de Aquino, Summa Theologiae, I-II, Q. 120 , Art. 1, Ed. Leonina, Roma, 1888).

24 "Et est nihil minus recta; peccatum enim non in lege neque in legis positore, sed in natura rei" (Aristoteles latinus. E-I,1137 b 1 y sgts, p. 382-77). 
tiva con su contenido de Justicia, pero vista en su relación con el caso concreto. ${ }^{25}$ La cabal comprensión de esa proporcionalidad permite la recta maduración del juicio de Equidad, el cual una vez alcanzado, obliga como ley que es de la conciencia. Es aquí donde el sentido práctico de tales juicios adquiere su mayor relevancia, pues del aplazamiento de su sentido práctico dependió en la modernidad, la supresión de la vigencia de los juicios de Equidad. Así Kant ${ }^{26}$ circunscribe la Equidad al foro interno de la conciencia, sosteniendo que aquella representa algo así como una cierta divinidad muda a la que no puede oirse y que consecuentemente, no puede tener fuerza obligatoria como en las doctrinas de Alberto y de Tomás.

Los juicios de Equidad tienen, desde el punto de vista de su aplicabilidad política, dos niveles de análisis. La consideración del caso más trivial acerca de tal aplicación posibilitará los materiales para una mejor comprensión de lo dicho. En efecto, decimos que si alguien entregó una espada en depósito y luego, llegado el momento de la restitución de aquel, su dueño vale decir el depositante, se hubiere vuelto loco, no procede la restitución de ley. Se trata evidentemente de una aplicación suspensiva del juicio de Equidad, pues, en virtud del mismo, se suspende la vigencia de aquel precepto legal que estipula la restitución de la garantía. Ahora bien, cuando el juez en este caso dispone la no restitución de la espada entregada en garantía, no solo mira el interés de su legítimo dueño, a saber del loco, a quien preserva de esta manera, de la comisión de un delito tal vez imputable, sino que mira principalmente la conveniencia del todo, o lo que es lo mismo en terminología albertino-tomista, el Bien Común Político. ${ }^{27}$

La ampliación moderadora 0 minorativa ${ }^{23}$ también ampliamente extendida entre los juristas, permitirá captar la inclusión de este concepto en la síntesis teológica elaborada en este caso, por Alberto Magno. Este último nivel del juicio de Equidad muestra también la conveniencia de observar el Bien del todo antes que el de las partes. Como surge de los textos de Aristóteles, de Alberto y de Tomás, la desviación o el desajuste no radica en la ley positiva, ni en la Justicia que la anima, sino antes bien en su aplicación al caso bajo ciertas condiciones. De este modo la obediencia a la ley positiva - y este es el punto de vista del ciudadano simple a quien también concierne el juicio de Equidad - bien puede resultar injusta. Dicho resumidamente, la ley no obliga a su incumplimiento. ${ }^{29}$ Entendemos aquí por cumplimiento antes que a la observancia meramente textual del precepto, al efectivo cumplimiento del fin de la ley.

${ }^{25}$ "Epieikes non deserit iustum simpliciter, sed iustum quod est lege determinatum" (Tomás de Aquino, Summa Theologicae, I-II, Q. 120, Art. 1, Ed. Leonina, Roma, 1888).

${ }^{26}$ Kant I., Metaphysik der Sitten, Rechtslehre, Wissentschaftliche Buchgesellschaft, Darmstadt, 1983, Bd. 7, p. 341-342.

${ }^{27}$ "Ambitus autem legis extendit se ad opera, qua sunt imperata per legem et ad intentionem legis, quam consequi vult per huiusmodi- vale decir los actos regidos por la Equidad- opera quae imperat, quod est salus rei publicae" (Albertus Magnus, op. cit., p. 380-12).

Qui oboedit ad intentionem legis, simpliciter oboedit; non enim est intentio legis obligare secundum legem ad illa quae contrariantur suae intentioni in quibus si praesens esset, aliter jubaret (Albertus Magnus, op. cit., p. 381-63). 
A propósito de lo dicho, Alberto ofrece dos ejemplos tomados de las Escrituras. Los ejemplos considerados por el maestro de Tomás sirven para aclarar el caso, usual entre nosotros, en el que por ejemplo, del cumplimiento de una obligación de entregar suma de dinero o cosa alguna, se sigue la completa ruina del deudor. En este caso la obligación de dar debe suspenderse, pues de su cumplimiento se seguiría un acto contrario al Bien Común y naturalmente al de las partes. El Doctor universalis justifica tanto el comer, en caso de necesidad extrema, del pan reservado a los sacerdotes ${ }^{30}$ como también el asumir la defensa armada de la Patria en días reservados para el culto. ${ }^{31}$ El perecer por causa del hambre o bien dejar la patria a merced de sus enemigos constituyen dos valores jurídicos más relevantes que el observar el sábado o el respetar el alimento de los sacerdotes. En el primer caso bien puede suspenderse el débito para con los sacerdotes con la clara y urgente necesidad de saciar las necesidades vitales del cuerpo mientras que en el segundo se suspende también el rigor que obliga a no tomar las armas con la finalidad de salvar al todo que es la patria.

A través de los modelos prácticos ofrecidos por Alberto fue posible integrar tres direcciones concurrentes al razonamiento practico. Ellas son la que emerge de un orden previo, la que emerge de la textura constitutiva del caso concreto y por último la que parte de la consideración del fin del todo político. Esos tres vectores se conjugan para dar sentido a las aplicaciones del juicio de Equidad en cualquiera de sus variantes analizadas. Unas breves consideraciones finales permitirán poner de manifiesto aquello que estuvo hasta ahora escondido como uno de los propósitos de esta exposición a saber, la significativa contribución que ofrece la Filosofía medieval para la resolución de importantes problemas actuales de la Filosofía Práctica.

\section{Consideraciones finales}

Los sistemas filosóficos de Alberto y de Tomás constituyen una totalidad coherente incluida dentro de otra a saber, la Teología. Esa actitud sistemática supone un realismo básico pues, las leyes divinas no se encuentran en la razón como intuidas de una vez y para siempre. Esas leyes o lo que es equivalente, la regularidad natural, se descubre por vía abstractiva, mediante una juiciosa captación de

30 La referencia corresponde en este caso a David en el Libro de los Reyes (I) 21-6 donde se dice: " $Y$ ahora, ¿Qué tienes a mano? Dame cinco panes en mi mano, o cualquier cosa que hallares. El sacerdote contestó a David, diciendo: Pan común no tengo a mano, mas hay pan santo, si es que tu gente se ha abstenido de mujeres. Respondió David al sacerdote y le dijo: Te aseguro que nos hemos abstenido de mujeres ayer y anteayer, desde cuando sali; los cuerpos de mi gente están puros; y aunque el viaje es profano, sin embargo se encuentran ahora santificados sus cuerpos. Dióle entonces el sacerdote pan santo, pues no había alli otro pan, sino solamente el pan de la proposición, que había sido retirado de la presencia de Yahvé..."

31 Se alude aquí al libro e los Macabeos II-39-41 donde dice: "En efecto, los enemigos los acometieron en día de sábado; y perecieron tanto ellos como sus mujeres, hijos y ganados, llegando a mil personas las que perdieron la vida. Supiéronlo Matatías y sus amigos e hicieron por ellos un gran duelo; y se dijeron unos a otros: Si todos nosotros hiciéremos como han hecho nuestros hermanos, y no peleáremos para defender nuestras vidas y nuestra ley contra las naciones, en breve tiempo nos exterminarán del país. Asi, pues, tomaron aquel día esta resolución: Si alguno, dijeron, nos acomete en día sábado, pelearemos contra él..." (Libro de los Macabeos, 38-41). 
todos y cada uno de los matices de lo real. El mundo real que Alberto y Tomás concibieron es un mundo ordenado, lo que viene a significar que su más íntima racionalidad - a la vez objeto de la inteligencia - solo puede comprenderse según que se la refiera a un prius et posterius. Dicho de otro modo, el mundo real en el que están incluidos los objetos de que las leyes se ocupan y en el que tienen su lugar las acciones que realizamos, constituye un orden que es análogo de otro orden superior.

Los juicios de Equidad en cuanto tales, captan lo esencial de los órdenes preestablecidos - el sobrenatural y el natural - y lo trasladan al caso concreto, a fin de que la resolución de las situaciones problemáticas permita reestablecer la Justicia, pero al mismo tiempo posibilite la reincardinación de esas acciones conflictivas dentro del todo de lo creado. Para Alberto y para Tomás no hay un orden natural separado del político y del juńdico. Muy lejos de sus sistemas está aquel estado de naturaleza del que, en virtud de su desorden, debe salirse por vía contractual. Concebirlo así sería formular veladamente una querella contra Dios, lo cual antes que una nota del pensamiento medieval, es el rasgo caraterístico de la modemidad.

El recurso a la lex divina que está inscrita en el interior del ordo naturae y del que la ratio constituye una de sus partes más perfectas, no constituye atentado alguno contra la seguridad jurídica. Por el contrario, Alberto y Tomás podrían responder a nuestros positivistas que así razonan, que es necesario pedir a Dios la solución de aquello que el juez humano no puede resolver. Como aquí se intentó demostrar, este pedido tiene también sus reglas que no son otras que las del recto razonamiento. Para tal cometido dispone la razón humana de un principio eficiente que son los llamados prima principia y de un marco que le sirve del mismo modo que las vías sirven a un tren, a saber del orden natural.

La Analogía conecta un orden con otro superior, de modo tal que entre el orden natural, el político y el jurídico que está en su interior, pueda establecerse una relación dinámica de vasos comunicantes. Así pues el juicio de Equidad se compone de dos direcciones una inductiva y la otra deductiva. En virtud de la primera capta la razón todos los matices de la realidad, en virtud de la segunda hace descender la armonía de los órdenes a la contingencia. Solo así puede sostenerse frente a las posiciones neopositivistas y deudoras del gnosticismo, que las palabras de Dios no están vaciadas de todo significado positivo. 